\title{
CONSTRUÇÃO DE UMA MEDIDA DE CLIMA CRIATIVO EM ORGANIZAÇÕES
}

\author{
CONSTRUCTION OF A CREATIVE CLIMATE \\ MEASURE INSTRUMENT IN ORGANIZATIONS
}

Mari Lucia Figueiredo CRESPO*

\begin{abstract}
RESUMO
Desenvolveu-se o presente estudo, que teve como objetivo definir as variáveis indicadoras de clima para a criatividade no ambiente organizacional. Para este fim, construiu-se um instrumento que foi aplicado a uma amostra de seis sujeitos de ambos os sexos, professores de uma Universidade Particular situada no interior de São Paulo. O instrumento citado é um questionário objetivo, baseado em estudos anteriores e contém 13 variáveis indicadoras de clima para a criatividade. As variáveis são: Motivação e Comprometimento, Dinamismo e Energia, Tempo para Idéias, Liberdade para Criar, Ludismo e Humor, Apoio às Idéias, Discussão e Debates, Ausência de Conflito, Confiança e Franqueza, Correr Risco, Suporte à Inovação, Salários e Benefícios e Tolerância às Diferenças. Os resultados foram aferidos pela análise de conteúdo das respostas decorrentes da coleta de dados. Os indicadores que tiveram menor número de respostas, ou seja, os mais difíceis de serem definidos foram: Motivação e Comprometimento e Dinamismo e Energia. Os resultados demonstraram uma boa consistência de conteúdos segundo as definições dos sujeitos e algumas definições coincidem com outras encontradas em estudos realizados no Brasil por outros pesquisadores. Podemos concluir que esses indicadores podem ser variáveis importantes no diagnóstico do clima para a criatividade no ambiente de trabalho.
\end{abstract}

Palavras-Chave: Indicadores de clima; criatividade; ambiente de trabalho.

\begin{abstract}
The present study was developed aiming to define indicative variables of climate to creativeness in the organizational environment. To carry out this

\footnotetext{
(*) Coordenadora do Curso de Psicologia da Fundação Educacional de Fernandópolis/SP - Doutoranda em Psicologia pela PUC-Campinas - Endereço para Correspondência: Av. Teotônio Vilela, s/n - Campus Universitário, Caixa Postal 120 - Fernandópolis/SP - E-mail: marifigueiredo@fef.br.
} 
study, an instrument was created and applied to a sample of six subjects of both genre, professors of a Private University in the inland of São Paulo state. The instrument is composed of an abjective questionnaire based on previons studies with 13 indicative variables of climate to creativeness. The variables are: Motivation and Commitment, Dynamism and Energy, Time for Ideas, Freedom to createve, Ludism and Humor, Support to Ideas, Discussion and Debates, Absence of Conflict, Trust and Openess, Risk-taking, Support to Innovation, Wages and Benefits and Tolerance to Differences. The results were checked by the analysis of the content of the answers from the Data Collection. The indications which had fewer answers, that is, the most difficult to be defined were: Motivation and Commitment and Dynamism and Energy. The results have shown a good consistency of contents according to the definitions of the subjects and some definitions are similar to other definitions found in studies coducted in Brazil by other researchers. We may conclude that these indications can be important variables in the diagnosis of climate to creativity in the work environment.

Key Words: Indicators of climate; Creativeness; Work environment.

\section{INTRODUÇÃO}

Avaliar a percepção de empregados em relação ao clima organizacional tem sido uma preocupação de organizações modernas, coma finalidade de adotar medidas de intervenção para melhorá-lo. O clima é importante para a produtividade da organização, na medida em que interfere diretamente na satisfação, na motivação e na criatividade dos empregados. Os estudos nesta área são particularmente úteis porque fornecem um diagnóstico da organização, bem como indicações de áreas carentes de atenção especial.

De acordo com Sá Leitão, Guimarães e Rosal (1998), existem vários estudos sobre clima organizacional. A maioria caracteriza-se como diagnóstico isolado e pontual, servindo, portanto, para uma organização, num determinado momento. São poucos os estudos que apresentam metodologia ou instrumento validado que possa ser utilizado para acompanhar a variação do clima organizacional e ser replicado em outras organizações. O acompanhamento do clima permite à organização monitorá-lo e tomar decisões para correção de problemas e fortalecimento de aspectos positivos existentes.

Clima organizacional tem sido apontado por alguns estudiosos como um fenômeno de relevância nas organizações, devendo ser conhecido para que se tenha um melhor entendimento das mesmas.

Segundo Payne \& Mansfield (1977), reconhecer que a organização é um ambiente psicologicamente significativo para seus membros tem levado ao conceito de clima organizacional. O referido autor afirma que existe interesse, tanto teórico como prático, em se investigar este tema. Em termos teóricos, aponta que por meio de análise abrangente de variáveis relevantes, aprofunda-se o estudo do funcionamento das organizações. Já no nível prático, a investigação sobre o clima organizacional oferece oportunidade para avaliação de diversos aspectos da organização, tais como estilos de liderança, criatividade e situações de ineficiência e de ineficácia do sistema. Esse autor conclui que o resultado de tudo isto é uma maior e melhor possibilidade de intervenção na organização.

Para Sá Leitão, Guimarães e Rosal (1998), existem na área do comportamento organizacional alguns assuntos que são de difícil compreensão e que se confundem em sua abrangência. Dentre esses, o clima organizacional é um dos mais confusos e mal compreendidos. A própria metáfora da qual se origina o termo clima denota a dificuldade em se precisar sua ocorrência e compreensão, quando se observa que as previsões do clima atmosférico dificilmente 
são precisas e seguras. A maior fonte desta confusão é fruto da grande dificuldade que se tem ao tentar definir clima organizacional.

Souza (1983), refletindo sobre essa questão, afirma que embora a palavra clima seja de entendimento comum como sinônimo de atmosfera, sua investigação e análise científica não são tão fáceis assim. Não há concordância na definição do termo, nem no desdobramento de seus fatores componentes. Percebe-se este problema ao se detectar a falta de clareza existente quanto à diferença entre o construto clima e o construto cultura.

Schneider (1985) afirma que, enquanto a pesquisa de clima tem se preocupado com as dimensões ou facetas das políticas que caracterizam um fenômeno organizacional particular (serviços, inovação), estudiosos de cultura desejam compreender: a) as normas e os sistemas de valores que ocasionam as políticas e atividades e b) os modelos com que as normas e valores são comunicados e transmitidos. Buscando aclarar esta questão, Denison (1996) defende a idéia de que a cultura se refere à essência da estrutura da organização que é enraizada nos valores, crenças e suposições sustentadas pelos membros da organização. Já o clima está sujeito aos aspectos do ambiente social que são conscientemente percebidos pelos membros da organização, sendo considerado relativamente temporário.

É possível observar que essas tentativas de diferenciação defendem, basicamente, a idéia segundo a qual clima estaria inserido dentro de um âmbito maior que diz respeito à cultura. Em outras palavras, pode-se associar a cultura com a filosofia que permeia a organização, com os valores responsáveis pela sua institucionalização, enquanto o clima seria associado às políticas empregadas para a consecução da filosofia existente e que são conseqüentes desta.

Sá Leitão, Guimarães e Rosal (1998), na revisão da literatura sobre clima organizacional, perceberam também uma constante confusão entre clima e satisfação no trabalho. Freqüentemente esta dificuldade diz respeito aos instrumentos de medida utilizados em estudos referentes a esses dois elementos, bem como à relação de causalidade entre eles.

Sims \& La Fallete (1975) ressaltam que, embora os estudos efetuados apontem para a existência de relação entre clima organizacional e satisfação, aceitar a afirmação de redundância ou de causalidade traz um elevado grau de subjetividade de julgamentos e que a questão da redundância só será resolvida por intermédio de pesquisas longitudinais com análises de causas. Assim, é possível discordar daqueles que afirmam que a pesquisa de clima pode ser nada mais do que a reinvenção do ciclo de satisfação. As descrições levam para uma classificação de clima como sendo orientado para descrição/ orientação e satisfação orientada para avaliação/ indivíduo.

Moran e Volkwein (1992) apresentam uma definição abrangente e esclarecedora, segundo a qual clima organizacional é uma característica relativamente duradoura de uma organização que a distingue das demais e: a) inclui percepções coletivas dos membros sobre sua organização com relação a dimensões como autonomia, confiança, coesão, apoio, reconhecimento, inovação, honestidade, criatividade, etc.; b) é produzido pela interação dos membros; c) serve como uma base para interpretar as situações; d) reflete as atitudes, normas e os valores prevalecentes da cultura da organização; e e) atua como uma fonte de influência para comportamentos apresentados.

É possível constatar a existência de alguns elementos fundamentais para a definição do construto clima. Primeiramente, está presente a referência à percepção como instrumento de sua detecção. Mas perceber o quê? É quando entram os atributos. Ao empregado é solicitado que explicite a percepção que ele tem da organização e que realize julgamentos sobre algumas de suas características, que resultam em atributos.

A partir desse elemento, aparece a indicação da multidimensionalidade dos aspectos que influenciam a percepção do clima. Esta pode abarcar variáveis individuais (história de vida, estrutura familiar, experiência profissional, valores, 
etc.) e variáveis da organização (tamanho da empresa, estrutura de comunicação, estilos de liderança, criatividade, etc.) que, juntas, compõem a definição dos atributos organizacionais. A percepção do empregado é influenciada por esses elementos e resulta no conceito que ele tem da organização.

As variáveis de um clima organizacional que promovam o talento criativo é uma das propostas deste trabalho. Em nossa concepção, o clima organizacional criativo somente ocorrerá caso haja apoio e valorização das novas idéias, por parte dos escalões superiores da organização. Esse clima organizacional constitui um dos prérequisitos indispensáveis para que as organizações se tornem criativas.

No entanto, é preciso abrir espaços para a criatividade que, sem dúvida, é essencial para as organizações atuais que pretendem superar os constantes desafios com os quais se defrontam em seu dia-a-dia. Tais desafios decorrem de novos problemas emergentes em um contexto globalizado e mutável, caracterizado por dinâmica acelerada e imprevisível. As soluções que vinham sendo adotadas nas últimas décadas já não atendem à realidade atual. Diante deste cenário, as empresas necessitam contar com pessoas que façam uso de seu potencial criador no trabalho, de forma a apresentar idéias novas para enfrentar os novos desafios.

De acordo com Bruno-Faria e Alencar (1998), uma análise da literatura indica que os estudos sobre criatividade se concentraram durante muito tempo mais nos fatores da personalidade criativa, com ênfase menor nas condições do ambiente de trabalho propícias à sua expressão. Mais recentemente, as influências socioambientais na criatividade passaram a ser mais enfatizadas, observando-se maior interesse por este fenômeno no contexto organizacional.

O valor atribuído à criatividade no âmbito das organizações é compartilhado por vários teóricos como, por exemplo, Ciotta (1987), que destaca ser necessário construir um ambiente criativo nas organizações, dando condições para o nascimento e desenvolvimento de uma cultura que reconheça o potencial ilimitado de seus empregados.

Ford \& Gioia (1995) também apontam fatores críticos que influenciam a produção de soluções criativas na organização.

Alencar (1996) descreve o perfil de uma organização criativa, ressaltando várias de suas características: valorização de idéias inovadoras, administração orientada para o futuro, estrutura organizacional marcada por autonomia e flexibilidade.

Embora reconhecida a importância da criatividade como algo vital às organizações, há poucas pesquisas sobre os fatores que influenciam a expressão do potencial criador dos empregados e raros são os instrumentos disponíveis para avaliá-los. Pela revisão de literatura, observou-se, por exemplo, que apenas reduzido número de instrumentos já foi construído. Um deles é a Escala de Apoio à Inovação (Siegel Scale of Support for Innovation - SSSI) - que foi desenvolvida por Siegel \& Kaemmerer (1978) para avaliar três aspectos distintos: o suporte à criatividade, a tolerância às diferenças e o comprometimento individual.

Foi também desenvolvido um inventário visando a avaliar especificamente distintas barreiras à criatividade, categorizando-as em estratégias de valores perceptuais e de auto-imagem (Rickards \& Jones). O instrumento, denominado Inventário Jones de Barreiras (The Jones Inventory of Barriers), visa identificar fatores inibidores do processo criativo e, por seus resultados, promover o autoconhecimento do empregado; pode ainda servir como veículo de desenvolvimento da organização.

O Inventário do Ambiente de Trabalho (Work Environment Inventory - WEI), construído por uma equipe do Centro para Liderança Criativa, dos Estados Unidos (Amabile \& Gryskiewicz, 1989), é um instrumento que identifica tanto estímulos à criatividade, como suporte do grupo de trabalho, disponibilidade de recursos, trabalho desafiante, quanto obstáculos à sua expressão no ambiente da organização, como pressão no trabalho. 
A importância de tratar a questão de medidas de clima propício à criatividade é nítida quando se observa o quanto os estudos que estão sendo realizados sobre este tema abordam as dificuldades de se encontrar um instrumento eficaz para sua medição. Considerando ainda, com base em revisão de literatura, que no Brasil não se encontram disponíveis instrumentos com tal finalidade, é imprescindível a realização de pesquisas que venham a contemplar essa questão. Essa necessidade é ainda mais premente pelo fato de as poucas medidas existentes serem originárias de outros países, com culturas diferentes e características diferenciadas de ambiente de trabalho.

Levantadas algumas questões quanto à delimitação do clima para a criatividade nas organizações, chega-se à problemática que sempre resulta quando acontece a má compreensão deste construto, que é a sua coleta de dados.

O interesse pelas questões acima levou a autora deste artigo a construir um instrumento de medida do clima que propicie a criatividade no ambiente de trabalho. O projeto atual começa com a definição das variáveis como indicadores da criatividade, que farão parte do instrumento.

\section{OBJETIVOS}

\section{Geral:}

Definir as variáveis indicadoras de clima para a criatividade no ambiente de trabalho.

\section{Específicos:}

- Construir um instrumento para avaliar o clima para a criatividade no trabalho;

- Verificar a validade de conteúdo do instrumento elaborado;

- Identificar a definição mais adequada dos indicadores para a criatividade.

\section{MÉTODO}

\section{Sujeitos}

A amostra desta pesquisa foi constituída por seis juízes, sendo três do sexo masculino e três do sexo feminino, com idades variando entre 37 e 58 anos. Com relação à formação, variou de doutorado incompleto a doutorado completo. Todos os sujeitos são docentes de nível superior.

\section{Instrumento}

\section{Questionário de indicadores de clima para a criatividade.}

O instrumento para a coleta de dados foi construído pela autora deste projeto, com a finalidade de verificar a compreensão dos indicadores que levam a um ambiente favorávelà criatividade.

O instrumento é composto de 13 indicadores divididos em dois questionários, que foram respondidos de forma aberta. Os indicadores são: motivação e comprometimento, dinamismo e energia, tempo para idéias, liberdade para criar, ludismo e humor, apoio às idéias, discussões e debates, ausência de conflito, confiança e franqueza, correr risco, suporte à inovação, salários e benefícios e tolerância às diferenças.

\section{Procedimento}

Os questionários foram distribuídos para os juízes, não sendo estabelecido o tempo de coleta. Assim que respondiam o referido instrumento, os mesmos o entregavam para a autora.

O questionário foi respondido individualmente e espontaneamente pelos participantes, sem a presença da autora da pesquisa, a partir das instruções nele contidas.

\section{RESULTADOS}

A proposta principal do presente estudo foi construir um instrumento que primeiramente 
definisse qual o significado dos indicadores de clima para a criatividade no ambiente de trabalho das organizações. Para atingir este objetivo foi solicitada a participação dos juízes que fizeram a definição dos indicadores.

Embora os resultados da análise de conteúdo tenham sido satisfatórios, destaca-se a necessidade de outras aplicações do instrumento a fim de confirmar os resultados encontrados. Este estudo será a primeira parte da validação de um questionário posteriormente criado e validado para diagnosticar o clima para a criatividade nas organizações.

Tendo em vista o objetivo para o qual o referido instrumento foi desenvolvido, decidiu-se por denominá-lo Indicadores de clima para a criatividade.

Passaremos agora para os resultados da análise de conteúdo a que foram submetidos os indicadores.

Conforme pode ser visto na Tabela 1, a análise revelou que os sujeitos definiram motivação como sendo um elemento estimulador para vencer desafios e o que move o indivíduo para criar. A variável comprometimento foi definida como: fidelidade aos compromissos, atingir metas e somar das modificações. Enquanto que a variável dinamismo foi definido como: dedicação e alcance de objetivos, força de vontade, participação em atividades e capacidade para inferir e atingir objetivos. Por fim, a variável energia, foi identificada como sendo: firmeza de caráter, realização de trabalho, força e vigor que leva à criação.

O indicador tempo para idéias foi assim definido: período dedicado à pesquisa, à elaboração e ao estabelecimento de objetivos e metas e espaço criado para discutir e colocar idéias em ação, conquista no trabalho. Quanto à liberdade para criar, a definição foi: espaço, autonomia, aplicar a nova realidade, senso de responsabilidade no próprio trabalho, obter alternativas e escolher o que pensar, Ludismo e humor foi classificado como: possibilidade leve de refletir sobre a realidade, disposição do que pensar, disposição de espírito, veia cômica, espírito de graça, a chave do bem-estar e das relações amigáveis.

Para apoio às idéias, as definições foram as seguintes: confiança nas idéias, respeito às opiniões divergentes dos empregados e ambiente acolhedor que leve à criatividade. Para discussão e debates escreveram-se: o bem-estar do grupo e da empresa, argumentação, diálogos para um consenso.

Ausência de conflito foi descrita como: relacionamento sem atritos entre trabalhador $\mathrm{e}$ equipe, ausência de registro de brigas e ausência de pendência sobre o caminho a ser adotado. Quanto à confiança e franqueza, a definição foi: respeito mútuo, assertividade e comprometimento, confiança nos outros e liberdade de expressão, confiança no caráter dos outros e expressão das posições adotadas.

Correr risco definiu-se assim: não ter medo de criar, espírito aventureiro, inovar e aceitar desafios, atributos para aceitar mudanças, romper com o passado e implementar nova situação. Suporte à inovação foi descrita como: apoio para mudança, diálogo e confiança, planejamento e definição de metas e estímulo à criatividade. Quanto aos salários e benefícios, as definições foram: reconhecimento do trabalho, remuneração adequada em decorrência do que se faz. E, por fim, em tolerância às diferenças escreveram: convívio harmonioso, respeito e paciência, aceitar as diferenças individuais, divergências de pontos de vista e propostas, conforme descrito na tabela 1.

Em seguida, apresentaremos os resultados da freqüência relativa das respostas dos indicadores do clima criativo. (vide Tabela 2).

Com podemos observar nesta tabela, todos os indicadores obtiveram $100 \%$ das respostas, sendo que os mais difíceis de serem definidos foram: Motivação e Comprometimento $(66,66 \%)$ e Dinamismo e Energia (83,33\%). 
Tabela 1. Definições dos Indicadores de clima para a criatividade.

\begin{tabular}{|c|c|}
\hline Indicadores & Definições \\
\hline Motivação e Comprometimento & $\begin{array}{l}\text { Elemento estimulador para vencer desafios e o que move o indivíduo } \\
\text { para criar. Ser fiel aos compromissos e atingir metas e soma das } \\
\text { modificações. }\end{array}$ \\
\hline Dinamismo e Energia & $\begin{array}{l}\text { Dedicação e alcançar objetivos, força de vontade } \\
\text { Participação em atividades e inferir para atingir objetivos } \\
\text { Firmeza de caráter, realização de trabalho, força e vigor que leva a } \\
\text { criação. }\end{array}$ \\
\hline Tempo para Idéias & $\begin{array}{l}\text { Período dedicado à pesquisa, elaboração e estabelecimento de } \\
\text { objetivos, metas, espaço criado para discutir e colocar idéias em } \\
\text { ação, conquista no trabalho }\end{array}$ \\
\hline Liberdade para Criar & $\begin{array}{l}\text { Espaço, autonomia, aplicar a nova realidade e senso de } \\
\text { responsabilidade sobre o próprio trabalho, obter alternativas e } \\
\text { escolher o que pensar. }\end{array}$ \\
\hline Ludismo e Humor & $\begin{array}{l}\text { Possibilidade leve de refletir sobre a realidade, disposição de } \\
\text { espirito, veia cômica, espirito de graça, a chave do bem estar e das } \\
\text { relações amigáveis. }\end{array}$ \\
\hline Apoio às Idéias & $\begin{array}{l}\text { Confiança nas idéias, respeito às opiniões divergentes dos } \\
\text { empregados e ambiente acolhedor que leve a criatividade. }\end{array}$ \\
\hline Discussões e Debates & $\begin{array}{l}\text { O bem estar do grupo e da empresa, argumentação, diálogos para } \\
\text { um consenso. }\end{array}$ \\
\hline Ausência de Conflito & $\begin{array}{l}\text { Relacionamento sem atritos entre trabalhador e equipe, ausência } \\
\text { de registro de brigas de pendência sobre o caminho a ser adotado. }\end{array}$ \\
\hline Confiança e Franqueza & $\begin{array}{l}\text { Respeito mutuo, assertividade e comprometimento, confiança nos } \\
\text { outros e liberdade de expressão, confiança no caráter dos outros e } \\
\text { expressão das posições adotadas. }\end{array}$ \\
\hline Correr Risco & $\begin{array}{l}\text { Não ter medo de criar, espirito aventureiro, inovar e aceitar desafios, } \\
\text { atributos para aceitar mudanças, romper com o passado e } \\
\text { implementar nova situação. }\end{array}$ \\
\hline Suporte à Inovação & $\begin{array}{l}\text { Apoio para mudança, dialogo e confiança, planejamento e definição } \\
\text { de metas e estímulo à criatividade. }\end{array}$ \\
\hline Salários e Benefícios & $\begin{array}{l}\text { Reconhecimento do trabalho, remuneração adequada e decorrência } \\
\text { do que se faz. }\end{array}$ \\
\hline Tolerância às Diferenças & $\begin{array}{l}\text { Convívio harmonioso, respeito e paciência, aceitar as diferenças } \\
\text { individuais, divergências de ponto de vista e propostas. }\end{array}$ \\
\hline
\end{tabular}


Tabela 2. Freqüência Relativa das Respostas dos Sujeitos.

\begin{tabular}{lc}
\hline Indicadores & $F(\%)$ \\
\hline Motivação e Comprometimento & 66,66 \\
Dinamismo e Energia & 83,33 \\
Tempo para Idéias & 100 \\
Liberdade para Criar & 100 \\
Ludismo e Humor & 100 \\
Apoio às Idéias & 100 \\
Discussões e Debates & 100 \\
Ausência de Conflito & 100 \\
Confiança e Franqueza & 100 \\
Correr Risco & 100 \\
Suporte à Inovação & 100 \\
Salários e Benefícios & 100 \\
Tolerâncias às Diferenças & 100 \\
\hline
\end{tabular}

\section{CONCLUSÃO}

O propósito principal da pesquisadora no presente estudo foi definir os indicadores de clima para a criatividade que, posteriormente, farão parte de um questionário, como variáveis que serão submetidas a uma análise fatorial para a validação do instrumento para uma realidade brasileira.

A análise de conteúdo dos indicadores demonstrou que, embora os juízes que participaram da pesquisa sejam de áreas distintas da Psicologia, as definições estão dentro do esperado, segundo a literatura dessa área.

Os resultados também encontrados neste estudo apontam que esses indicadores possuem consistência suficiente para possibilitar diagnósticos de clima para a criatividade em ambiente organizacional, uma vez que os mesmos foram respondidos adequadamente, sua compreensão atingiu o nível satisfatório e o conteúdo das respostas foi condizente com o esperado.
De qualquer sorte, é possível afirmar que esses indicadores podem ser utilizados em qualquer tipo de ambiente organizacional, desde que os respondentes tenham um nível de escolaridade a partir de segundo grau. Este fato indica a sua complexidade, dificultando a sua aplicação em pesquisas junto a indivíduos com nível de escolaridade abaixo do mencionado.

Destaca-se, ainda, que a multiplicidade dos indicadores envolvidos no estudo da criatividade no contexto das organizações é necessária, uma vez que são vários os aspectos do ambiente de trabalho que atuam como estímulos e barreiras à sua expressão.

Parece importante ainda reforçar que o ambiente éapenas um dos fatores que influenciam a expressão da criatividade e que aspectos pessoais daqueles que executam o trabalho, além das interações entre indivíduos e seus ambientes, constituem também importantes fatores.

Sendo assim, o indicador Tolerância às Diferenças se faz necessário para a composição do questionário de clima para a criatividade.

\section{REFERÊNCIAS BIBLIOGRÁFICA}

ALENCAR, E. M. L. S. (1996). A gerência da criatividade. Makron Books, São Paulo.

AMABOLE, T. M. e GRYSKIEWICZ, N. D. (1989). The creative environment scales: work environment inventory. Creativity Research Journal, n.2, p.231-253.

BRUNO-FARIA, M. F. e ALENCAR, E. M. L. S. (1998). Estímulos e barreiras à criatividade no ambiente de trabalho. Revista de Administração, v.33, n.4, p.86-91, out/dez.

CIOTTA, P. (1987). The anatomy of a creative corporate culture. Journal of Creative Behavior, v.21, n.2, p.145-152.

DENISON, D. R. (1996). What is the difference between organizational culture and organizational climate? A native s point of view on a decade of paradigm wars. Academy of Management Review, v.21, n.3, p.619-654. 
FORD, C. M. e GIOIA, D. A. (1995). Multiple visions and multiple voices academic and practitioner conceptions of creativity in organizations. In: Ford, C. M. e Gioia, D.A. (orgs.) Creative action in organizations. London, Sage Publications, p.3-11.

MORAN, E. T. e VOLKWEIN, J. F. (1992). The cultural approach to the formation of organizational climate. Human Relations, v.45, n.1.

PAYNE, R. L. e MANSFIELD, R. (1977). Relationships of perceptions of organizational climate to organizational structure, context and hierarquical position. Administrative Science Quarterly, v.18, n.4, p.515-26.

RICKARDS, T. e JONES, L. J. (1991). Towards the identification of situational barriers to creative behaviors. The development of a self-report inventory. Creativity Research Journal, v.4, n.4, p.303-315.

SÁ LEITÃO, J. S., GUIMARÃES T. A. e ROSAI, M. A.A. (1997). Metodologia de diagnóstico de clima organizacional em ambiente de inovação tecnológica. ENANPAD. Foz do Iguaçu.

SCHNEIDER, B. (1985). Organizational behavior. Annual Review of Psychology, v.36, p. 573-611.

SIEGEL, S. M. e KAEMMERER, W. F. (1978). Measuring the perceived support for innovation in organizations. Journal of Applied Psychology, v.63, n.5, p.553-562.

SIMS, Jr. H. P. e LA FALLETTE, W. R. (1975). Is satisfaction redundant with organizational climate? Organizational Behavior and Human Performance, v.13, p.267-278.

SOUZA, E. L. P. (1983). Clima e estrutura de trabalho. Revista de Administração, v.18, n.3, p.14-18.

Recebido para publicação em 30 de outubro de 2003 e aceito em 3 de maio de 2004. 
